\title{
Aggressive behavior during the first 24 hours of psychiatric admission
}

\author{
Comportamento agressivo durante as primeiras 24 horas \\ de internação psiquiátrica
}

\author{
Vitor Crestani Calegaro, ${ }^{1}$ Amanda Bolson Dotto, ${ }^{2}$ Denise Freitas, ${ }^{2}$ Anderson Barcellos Brum, ${ }^{2}$ Andrei Garziera Valerio, ${ }^{2}$ \\ Christina Chitolina Schetinger, ${ }^{3}$ Angelo B. M. Cunha ${ }^{4}$
}

\begin{abstract}
Objective: To investigate the association between aggression in the first 24 hours after admission and severity of psychopathology in psychiatric inpatients.

Methods: This cross-sectional study included psychiatric patients admitted to Hospital Universitário de Santa Maria, in Santa Maria, southern Brazil, from August 2012 to January 2013. At their arrival at the hospital, patients were interviewed to fill in the Brief Psychiatric Rating Scale (BPRS) form, and any aggressive episodes in the first 24 hours after admission were recorded using the Overt Aggression Scale (OAS). The Mann-Whitney $U$ test was used to compare patients according to aggressiveness: aggressive versus non-aggressive, hostile versus violent, and aggressive against others only versus self-aggressive.

Results: The sample was composed of 110 patients. Aggressive patients in general had higher BPRS total scores ( $p=0.002)$ and individual component scores, and their results showed more activation $(p<0.001)$ and thinking disorders $(p=0.009)$, but less anxious-depression $(p=0.008)$. Violent patients had more severe psychomotor agitation $(p=0.027)$, hallucinations $(p=$ $0.017)$ and unusual thought content $(p=0.020)$. Additionally, self-aggressive patients had more disorientation $(p=0.011)$ and conceptual disorganization $(p=0.007)$.

Conclusions: Aggression in psychiatric patients in the first 24 hours after admission is associated with severity of psychopathology, and severity increases with severity of patient psychosis and agitation.
\end{abstract}

Keywords: Aggression, psychopathology, psychiatric emergency services, Brief Psychiatric Rating Scale.

\section{Resumo}

Objetivo: Avaliar a relação entre agressividade nas primeiras 24 horas após admissão e a gravidade da psicopatologia de pacientes psiquiátricos.

Métodos: Este estudo transversal foi realizado no Hospital Universitário de Santa Maria, na região sul do Brasil, com pacientes admitidos entre agosto de 2012 e janeiro de 2013. Ao chegar ao hospital, os pacientes foram entrevistados para completar a Escala Breve de Avaliação Psiquiátrica (BPRS), e todos os episódios de agressão nas primeiras 24 horas após a admissão foram registrados usando a Escala de Agressividade Declarada (OAS). $O$ teste $U$ de Mann-Whitney foi usado para as comparações entre pacientes agressivos e não-agressivos, hostis e violentos, e agressivos contra outros apenas ou autoagressivos. Resultados: A amostra tinha 110 pacientes. Em geral, pacientes agressivos tiveram escores mais altos na escala BPRS $(p=0.002)$ e nos itens individuais, e exibiram mais ativação $(p<0.001)$ e distúrbios de pensamento $(p=0.009)$, mas menos ansiedadedepressão ( $p=0.008)$. Os pacientes violentos tiveram escores mais altos para excitação $(p=0.027)$, comportamentos alucinatórios ( $p$ $=0.017)$ e alteração de conteúdo do pensamento $(p=0.020)$. Além disso, os pacientes autoagressivos mostraram maior desorientação $(p=0.011)$ e desorganização conceitual $(p=0.007)$.

Conclusões: A agressão em pacientes psiquiátricos nas primeiras 24 horas da admissão é relacionada a gravidade da psicopatologia, a qual aumenta à medida que a gravidade da psicose e a excitação do paciente aumentam.

Descritores: Agressão, psicopatologia, serviços de emergência psiquiátrica, Escala Breve de Avaliação Psiquiátrica

\footnotetext{
${ }^{1}$ Psychiatrist. MSc. Replacement Professor, Department of Neuropsychiatry, Universidade Federal de Santa Maria (UFSM), Santa Maria, RS, Brazil. ${ }^{2}$ Psychiatry resident, Department of Neuropsychiatry, UFSM, Santa Maria, RS, Brazil. ${ }^{3}$ Medical student, UFSM, Santa Maria, RS, Brazil. ${ }^{4}$ Psychiatrist. PhD. Adjunct Professor, Department of Neuropsychiatry, UFSM, Santa Maria, RS, Brazil.

This article is a part of the first author's Master's dissertation entitled "Psychiatric inpatient aggression" ("Agressividade em Pacientes Psiquiátricos Internados"), presented at the Health Sciences Professional Master's Program, at Universidade Federal de Santa Maria (UFSM), Santa Maria, RS, Brazil, in May 2013. Partial results were presented at the World Congress on Brain, Behavior and Emotions, held in 2013 in São Paulo, SP, Brazil.

Financial support: The study was supported by Programa de Bolsas de Iniciação Científica e Auxílio à Pesquisa - Hospital Universitário de Santa Maria (PROICHUSM), Universidade Federal de Santa Maria (UFSM), Santa Maria, RS, Brazil.

Submitted May 14 2014, accepted for publication Jul 08 2014. No conflicts of interest declared concerning the publication of this article.

Suggested citation: Calegaro VC, Dotto AB, Freitas D, Brum AB, Valerio AG, Schetinger CC, et al. Aggressive behavior during the first 24 hours of psychiatric admission. Trends Psychiatry Psychother. 2014;36(3):152-159. http://dx.doi.org/10.1590/2237-6089-2014-0016
} 


\section{Introduction}

Aggression against others or towards oneself is an important reason why individuals with mental disorders are taken to psychiatric emergency services (PES). ${ }^{1}$ Voluntary or involuntary hospitalization is often recommended to protect both patients and others..$^{2,3}$ Aggressive behaviors, not unusual during psychiatric hospitalizations, may generate mild to severe physical and psychological damages for both patients and hospital staff. Moreover, they entail medical expenses, absences from work and legal charges. ${ }^{4,5}$

Several studies have been conducted to identify associated riskfactors, but cultural, ethnic, methodological and conceptual differences complicate generalizations, as results are often conflicting. 6,7 Steinert conducted a review and concluded that the variables associated with aggression in psychiatric inpatients are different from those found in the general community, and that the most important predictor is life history of aggression. Studies in the literature report different findings regarding sex, age, diagnosis and alcohol abuse and aggression in hospital settings. ${ }^{6,7}$ These characteristics may play a minor role, whereas clinical and psychopathologic variables, such as delusions, are more prominent. ${ }^{7}$ Therefore, clinical and psychopathological features associated with aggression should be identified to recognize, at an early stage, patients at risk to become aggressive when hospitalized. The Brief Psychiatric Rating Scale (BPRS) has been used around the world for over 50 years and adapted over time. ${ }^{8,9}$ Although its main function is to compare changes in psychopathology, studies have revealed an association between factors of this scale and aggression in hospital environments. ${ }^{10-14}$ This study assessed the severity of psychopathology and investigated possible associations with aggressive behaviors in the first 24 hours after psychiatric hospitalization to define whether aggressiveness was associated with the severity of psychosis and psychomotor agitation.

\section{Methods}

\section{Participants}

This cross-sectional study was conducted in a public tertiary care general hospital, Hospital Universitário de Santa Maria (HUSM), in Santa Maria, southern Brazil, in which psychiatric services are provided in a psychiatric emergency department (PED) and a psychiatric unit (PU). HUSM is a reference hospital serving an area of 500,000 inhabitants in the central region of the state of Rio Grande do Sul, Brazil. The PED, the interface between the population and the hospital, has an observation room with two beds. The PU is a mixed, closed-door unit with 25 beds for short-term hospitalizations.

Patients may be referred by health services of the region or arrive directly at the $P E D$, the entrance to the hospital. In this department, patients may stay for up to 72 hours, after which they must be discharged or transferred to the PU or other hospitals. Admissions are registered using the Hospital Admission Authorization (HAA) form, a document signed when patients stay past midnight or when they are immediately transferred to the PU. In this study, we included registered admissions only and excluded patients that stayed in the hospital for observation only.

The psychiatric service of HUSM does not provide any specific treatment for substance abuse, but psychomotor agitation and aggressiveness are common in patients that use drugs. In these cases, admission is often necessary as an emergency procedure, and patients are transferred to other hospitals at the earliest time possible.

Inclusion criteria were: 1) psychiatric hospitalization; and 2) age between 18 and 65 years. Exclusion criteria were: 1) patients with delirium; and 2) substance use. These patients were excluded to avoid confounding factors in the study of psychotic characteristics. All patients underwent routine clinical examination and laboratory and imaging tests, if necessary, to rule out possible organic diseases. A physician was called for further evaluations in case any abnormality was found.

\section{Measures}

The following psychometric scales were used for assessments: BPRS and Overt Aggression Scale (OAS), both translated and validated for Portuguese. BPRS is widely used to assess psychopathologies. We used an 18-item anchored version scoring 0-6 according to the severity of the symptoms. ${ }^{15} \mathrm{~A}$ Structured Interview Guide was used to increase inter-rater reliability. ${ }^{16}$ The scale items may be classified into four components (factors): anxious-depression, withdrawal-retardation, thinking disorder and activation. ${ }^{17}$ The OAS, used in several other studies, ${ }^{18,19}$ is an instrument to measure aggressive episodes. Easily applicable, it classifies aggressive episodes into four types: verbal aggression, aggression against objects, self-aggression and physical aggression against others. A form was developed to collect variables about demographic characteristics, disease history, use of services, history of aggression, previous treatments and psychopathological features.

The study was conducted by the Psychiatry Research Laboratory team, which includes residents in psychiatry, 
medicine undergraduates and a coordinator. All were trained to use the study instruments before data collection and during the pilot phase. On the first 40 days, a pilot study was carried out to correct possible flaws in data collection and gather data for sample calculation. At this stage, the scales were applied under the assistance of a supervisor. Inter-rater reliability was not been tested objectively. Thirty patients were included in the study.

\section{Procedures}

Data were collected from August 2012 to January 2013, and the sampling method was by convenience. An attempt was made to include all inpatients that met inclusion criteria in those 6 months. Some of the authors visited the PED daily, gathered data about hospitalizations in the last 24 hours, interviewed patients and reviewed medical records to fill out the study form.

One of the authors was exclusively assigned to apply the OAS scale by interviewing the patient and a family member, as well as talking to the nursing staff and the attending physicians. As several aggressive incidents may be part of the same episode, which may last for hours, we considered each 24-hour period as an episode.

Six resident physicians were responsible for filling out the scales after interviewing the patients, which should be done within 24 hours of admission, taking into account patient condition at admission.

Diagnosis were assessed by the PED and PU medical teams according to their service routines. During patient stay in the hospital, diagnosis were discussed with the resident's supervisor and recorded in the chart at discharge using the 10th revision of the International Classification of Diseases (ICD-10). No specific diagnostic instruments were used because of the practical difficulties of their application, such as the time necessary to fill in the questionnaire and the patient conditions in the emergency department, sometimes agitated and sometimes sedated. In addition, our purpose was not to associate diagnosis and aggression, because diagnoses were less important than clinical and psychopathological characteristics in our study.

Each admission was counted separately, regardless of how many times the patient had been admitted in the period. The same patients may have a different psychopathological condition each time they are admitted, and may be either aggressive or not.

When data collection was concluded, all the forms were reviewed. After that, data were entered into Excel by two operators, to avoid typing errors. This study was approved by the Research Ethics Committee of Universidade Federal de Santa Maria and was registered in the Brazilian Research Ethics Database (Plataforma Brasil; CAAE
02232612.3.0000.5346). An informed consent form was signed by the patients, their relatives or legal guardians.

\section{Statistical analysis}

Data were analyzed using PASW Statistics 17.0. Variables were analyzed descriptively, and results were distributed in frequency tables. Data that could not be retrieved were classified as lost and excluded from the analysis. We controlled data for age, sex, demographic characteristics and diagnosis, and a chi-square test and the Fisher exact test were used to compare differences between groups.

The sample was first divided into aggressive and non-aggressive individuals. Aggressive individuals were then separated into hostile (verbally aggressive and aggressive against objects) and violent (physically aggressive). After that, aggressive individuals were divided into those that were aggressive against others only (hetero-aggressive), and those that were also aggressive towards themselves (self-aggressive). The groups were compared using the Mann-Whitney $U$ test. The level of significance was set at 5\% ( $\alpha=0.05)$. The prevalence of aggression was described with $95 \%$ confidence intervals $(95 \% \mathrm{CI})$.

\section{Results}

During the study, 1,625 persons were seen in the PED, and 259 were taken to the observation room; $16 \%$ of the patients remained under observation, and only $9.4 \%$ were hospitalized. Of the eligible patients, 13 were discharged during the night, before the authors visited to the PED in the morning and were not included. Therefore, the final sample was composed of 110 subjects (Figure 1 ).

\section{Sample characteristics}

Most hospitalized patients were white and had little schooling (Table 1). Most men were young single adults without children, and women were 30 to 50 years old, married, with more than one child. The proportion of men and women did not differ statistically $\left(\chi_{(1)}^{2}=0.582 ; p=0.446\right)$. Most patients in the sample presented had psychotic symptoms, such as delusions and hallucinations. Only a few reported suicide attempts leading to hospitalization, and most were admitted involuntarily because of the risk of aggression.

The analysis of diagnoses revealed a significant positive association between aggression and bipolar disorder, although not for manic episodes. Negative associations were found for depressive mood disorders. 


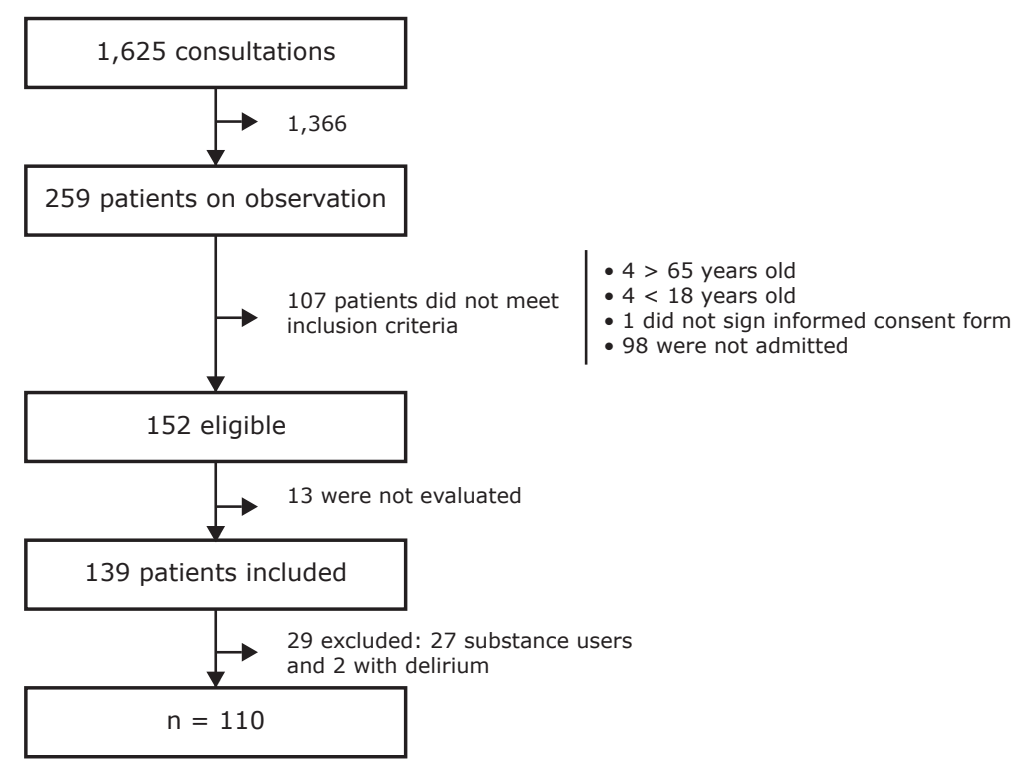

Figure 1 - Sample composition.

In the first 24 hours after admission, 40 (36.4\%) patients showed some aggressiveness (Table 2). There was a predominance of verbal aggressiveness, in 37 (33.6\%) patients, and of these, 24 (60.0\%) were aggressive only verbally. Physical aggression and aggression against objects was found in 10 (9.1\%) and $11(10.0 \%)$ patients. Surprisingly, all self-aggressive patients were also verbally aggressive; three were aggressive against objects and two, physically aggressive against others, which revealed the high degree of aggressiveness of these patients.

\section{Psychopathology and aggressive behavior}

Aggressive patients had a higher BPRS mean score than non-aggressive patients (Table 3 ). The differences were significant, with a positive association for all components, except for withdrawal-retardation.

Aggressiveness was associated with psychomotor agitation, somatic anxiety and exaggerated self-esteem, in the group of activating symptoms. It was also associated with hostility, suspiciousness and conceptual disorganization, in the thinking disorder component.

Although aggressive patients had higher withdrawalretardation scores, they were less willing to cooperate in the interview and had fewer negative symptoms, such as psychomotor retardation. In addition, aggressive individuals had fewer depressive symptoms (depressive mood and feelings of guilt).

We also compared the BPRS scores between hostile (verbally aggressive and aggressive against objects) and violent (physically aggressive) patients, and violent individuals had a higher score (Table 4). A positive association was found for withdrawal-retardation and thinking disorder. Violent individuals showed more symptoms of psychomotor agitation and anger (hostility) than those who were only hostile, as mentioned above. However, they also had more hallucinations and delusions (unusual thought content), and their mean scores for these items were high. They also had higher scores for emotional withdrawal and specific motor disturbances. The comparison of violent and hostile patients did not reveal any significant association with exaggerated selfesteem and suspiciousness.

Finally, after comparing patients that were aggressive against others (only) and self-aggressive, we found that self-aggressive patients had greater psychomotor agitation, somatic anxiety, conceptual disorganization and disorientation, but no significant differences in depressive symptoms. Therefore, self-aggressive individuals had the most severe psychopathologies (greatest BPRS scores).

\section{Discussion}

This study revealed that the higher the BPRS scores, the more severe the aggression, and that self-aggressive individuals formed the most aggressive group. This result was true both for the scale as a whole and for its components, except for anxious-depression, which was negatively associated with aggressiveness (Figure 2). 
Table 1 - Sample characteristics according to aggression during the first 24 hours $(n=110)$

\begin{tabular}{|c|c|c|c|c|c|}
\hline & \multicolumn{2}{|c|}{ No } & \multicolumn{2}{|c|}{ Yes } & \multirow[b]{2}{*}{ p* } \\
\hline & $\mathbf{n}$ & $\%$ & $\mathbf{n}$ & $\%$ & \\
\hline \multicolumn{6}{|l|}{ Age (years) } \\
\hline $18-25$ & 6 & 8.6 & 8 & 20.0 & 0.400 \\
\hline $26-35$ & 27 & 38.6 & 13 & 32.5 & \\
\hline $36-45$ & 11 & 15.7 & 4 & 10.0 & \\
\hline $46-55$ & 18 & 25.7 & 12 & 30.0 & \\
\hline $56-65$ & 8 & 11.4 & 3 & 7.5 & \\
\hline \multicolumn{6}{|l|}{ Sex } \\
\hline Male & 35 & 50.0 & 24 & 60.0 & 0.312 \\
\hline Female & 35 & 50.0 & 16 & 40.0 & \\
\hline \multicolumn{6}{|l|}{ Education } \\
\hline Incomplete primary school & 36 & 52.9 & 22 & 55.0 & 0.966 \\
\hline Complete primary school & 9 & 13.2 & 5 & 12.5 & \\
\hline Complete high school & 16 & 23.5 & 10 & 25.0 & \\
\hline Complete college & 7 & 10.3 & 3 & 7.5 & \\
\hline \multicolumn{6}{|l|}{ Ethnicity } \\
\hline White & 52 & 74.3 & 24 & 60.0 & 0.119 \\
\hline Non-white & 18 & 25.7 & 16 & 40.0 & \\
\hline \multicolumn{6}{|l|}{ Marital status } \\
\hline Single & 31 & 44.3 & 17 & 42.5 & 0.557 \\
\hline Married & 20 & 28.6 & 14 & 35.0 & \\
\hline Divorced & 16 & 22.9 & 9 & 22.5 & \\
\hline Widowed & 3 & 4.3 & 0 & 0.0 & \\
\hline \multicolumn{6}{|l|}{ Occupational status } \\
\hline Unemployed & 33 & 47.1 & 23 & 57.5 & 0.291 \\
\hline Employed & 14 & 20.0 & 6 & 15.0 & \\
\hline Illness aid & 11 & 15.7 & 2 & 5.0 & \\
\hline Retired & 12 & 17.1 & 9 & 22.5 & \\
\hline \multicolumn{6}{|l|}{ Clinical features } \\
\hline Psychosis (delusions/hallucinations) & 55 & 78.6 & 36 & 90.0 & 0.137 \\
\hline Suicide attempt & 15 & 21.4 & 5 & 12.5 & 0.243 \\
\hline \multicolumn{6}{|l|}{ Diagnoses } \\
\hline \multicolumn{6}{|l|}{ Axis I diagnoses } \\
\hline Schizophrenia. schizotypal and delusional disorders (F20-F29) & 16 & 22.9 & 7 & 17.5 & 0.628 \\
\hline Schizophrenia (F20) & 6 & 8.6 & 2 & 5.0 & 0.708 \\
\hline Schizoaffective disorders (F25) & 5 & 7.1 & 2 & 5.0 & 1.000 \\
\hline Psychosis not otherwise specified (F29) & 5 & 7.1 & 3 & 7.5 & 1.000 \\
\hline Mood Disorders (F30-F39) & 41 & 58.6 & 29 & 72.5 & 0.156 \\
\hline Bipolar affective disorder (F31) & 30 & 42.9 & 29 & 72.5 & 0.003 \\
\hline Manic or mixed episode & 23 & 76.7 & 26 & 89.7 & 0.299 \\
\hline Depressive episode & 5 & 16.7 & 2 & 6.9 & 0.424 \\
\hline Major or recurrent depression (F32-F33) & 11 & 15.7 & 0 & 0.0 & 0.007 \\
\hline Unspecified mood disorder (F39) & 1 & 1.4 & 0 & 0.0 & 1.000 \\
\hline Other diagnosis & 2 & 2.9 & 0 & 0.0 & 0.533 \\
\hline No axis I diagnosis & 12 & 17.1 & 4 & 10.0 & 0.404 \\
\hline \multicolumn{6}{|l|}{ Axis II diagnoses } \\
\hline Personality disorders (F60-F69) & 31 & 44.3 & 13 & 32.5 & 0.312 \\
\hline Borderline personality disorder (F63) & 15 & 21.4 & 5 & 12.5 & 0.309 \\
\hline Dissocial personality disorder (F62) & 1 & 1.4 & 2 & 5.0 & 0.299 \\
\hline Personality disorders NOS (F60.9) & 15 & 21.4 & 8 & 20.0 & 1.000 \\
\hline Mental retardation (F70-F79) & 10 & 14.3 & 5 & 12.5 & 1.000 \\
\hline
\end{tabular}

Data express column percentages.

* $\mathrm{p}$ values calculated using a chi-square test for general characteristics and the Fisher exact test for diagnoses. 
Table 2 - Prevalence of aggression during the first 24 hours after psychiatric admission $(\mathrm{n}=110)$

\begin{tabular}{lccc}
\hline \multicolumn{4}{c}{ after psychiatric admission $(\mathrm{n}=110)$} \\
\hline Aggression (any type) & $\mathbf{n}$ & $\mathbf{\%}$ & $\mathbf{9 5 \%} \mathbf{C I}$ \\
Verbal aggression & 40 & 36.4 & $27.3-44.5$ \\
Aggression against objects & 11 & 33.6 & $25.5-41.8$ \\
Physical aggression & 10 & 9.1 & $3.6-14.5$ \\
Self-aggression & 5 & 4.5 & $0.9-8.2$ \\
\hline
\end{tabular}

$95 \% \mathrm{CI}=95 \%$ confidence interval.

According to Steinert, the most important predictors of aggressive behavior are life history of aggression and severity of pathology. ${ }^{7}$ We agree with Amore et al. and Biancosino et al., who claim that aggressive individuals have higher scores on the BPRS scale. ${ }^{10,11}$ In contrast, non-aggressive patients tend to have more depressive and negative symptoms.

Our findings are in accordance with those reported in previous studies. For example, Colasanti found that excitement/activation is more closely associated with verbal and physical aggression. ${ }^{12}$ Raja \& Azzoni demonstrated that hostile and violent individuals have higher scores on the hostility/agitation component and lower scores on the anxious-depression component than non-aggressive patients. ${ }^{14}$ Amore et al. confirmed the association of disorder severity (higher overall score on BPRS) and claimed additionally that the hostility/suspiciousness component is a predictor of verbal aggression turning into physical aggression. ${ }^{10}$ Huber et al. described a possible factor of excitement of BPRS, composed of hostility, excitement and lack of cooperation, and found that this factor is associated with aggressiveness, risk or attempt of suicide and involuntary hospitalization. ${ }^{13}$

In the analysis of the factors suggested by Crippa et al., we found a positive association between activation and thinking disorder, as well as a negative association with anxious-depression. ${ }^{17}$ Although no association was found for the withdrawal-retardation component, uncooperativeness had a positive association, which in our study seems to be actually associated with psychomotor agitation and psychotic symptoms. The Brazilian version of the BPRS scale has its own components, slightly different from those found in the foreign literature, but the associations found in our study point to the same direction and suggest that aggressiveness in the hospital is linked to agitation and psychosis.

Within the group of aggressive individuals, violent patients had the most severe psychopathologies. Hostility and psychomotor agitation are associated with any type of aggressiveness in the first 24 hours, and scores were higher for violent patients than for hostile patients. Nevertheless, these patients' behaviors were significantly influenced by hallucinations and delusions. Although most of the individuals in the sample had mood disorders, about 4 in 5 had psychotic symptoms. The simple presence of these symptoms was not associated with aggression. However, our findings suggested that the difference in violent patients was the fact that their behavior was affected by hallucinations and delusions in a context of psychomotor agitation and anger. The severity of psychosis may increase with severity of aggression. Moreover, violent patients exhibited more emotional withdrawal and specific motor disturbances, common symptoms of psychosis.

Table 3 - Mean scores obtained on the Brief Psychiatric

Rating Scale and comparison between aggressive and non-aggressive patients $(n=101)$

\begin{tabular}{|c|c|c|c|}
\hline & $\begin{array}{c}\text { Non } \\
\text { aggressive }\end{array}$ & Aggressive & $\mathbf{p}$ \\
\hline Total score & 34.7 & 42.3 & $0.002 *$ \\
\hline Anxious-depression & 8.6 & 5.1 & $0.008 *$ \\
\hline 1. Somatic concern & 1.0 & 0.6 & 0.079 \\
\hline 2. Anxiety (psychic) & 2.8 & 2.4 & 0.321 \\
\hline $\begin{array}{l}\text { 5. Self-depreciation } \\
\text { and guilt feelings }\end{array}$ & 2.0 & 1.1 & $0.033 *$ \\
\hline 9. Depressive mood & 2.8 & 1.1 & $0.001 *$ \\
\hline Withdrawal-retardation & 6.0 & 7.5 & 0.149 \\
\hline $\begin{array}{l}\text { 3. Emotional } \\
\text { withdrawal }\end{array}$ & 1.9 & 2.0 & 0.890 \\
\hline $\begin{array}{l}13 . \text { Psychomotor } \\
\text { retardation }\end{array}$ & 0.9 & 0.2 & $0.009 *$ \\
\hline 14. Uncooperativeness & 0.7 & 2.4 & $<0.001^{*}$ \\
\hline $\begin{array}{l}\text { 16. Blunted or } \\
\text { inappropriate affect }\end{array}$ & 1.4 & 1.1 & 0.228 \\
\hline $\begin{array}{l}\text { 18. Disorientation and } \\
\text { confusion }\end{array}$ & 1.1 & 1.8 & 0.248 \\
\hline Thinking disorder & 14.7 & 18.4 & $0.009 *$ \\
\hline $\begin{array}{l}\text { 4. Conceptual } \\
\text { disorganization }\end{array}$ & 1.8 & 2.8 & $0.023 *$ \\
\hline 10. Hostility & 3.6 & 4.7 & $<0.001^{*}$ \\
\hline 11. Suspiciousness & 3.0 & 4.1 & 0.039* \\
\hline 12. Hallucinations & 2.8 & 2.9 & 0.761 \\
\hline $\begin{array}{l}\text { 15. Unusual thought } \\
\text { content }\end{array}$ & 3.5 & 4.1 & 0.212 \\
\hline Activation & 5.5 & 11.3 & $<0.001^{*}$ \\
\hline 6. Anxiety (somatic) & 1.8 & 3.7 & $<0.001 *$ \\
\hline $\begin{array}{l}\text { 7. Specific motor } \\
\text { disturbances }\end{array}$ & 0.7 & 0.9 & 0.517 \\
\hline $\begin{array}{l}\text { 8. Exaggerated } \\
\text { self-esteem }\end{array}$ & 1.5 & 2.6 & $0.015^{*}$ \\
\hline $\begin{array}{l}\text { 17. Psychomotor } \\
\text { agitation }\end{array}$ & 1.6 & 4.2 & $<0.001^{*}$ \\
\hline
\end{tabular}

* Significant values. 


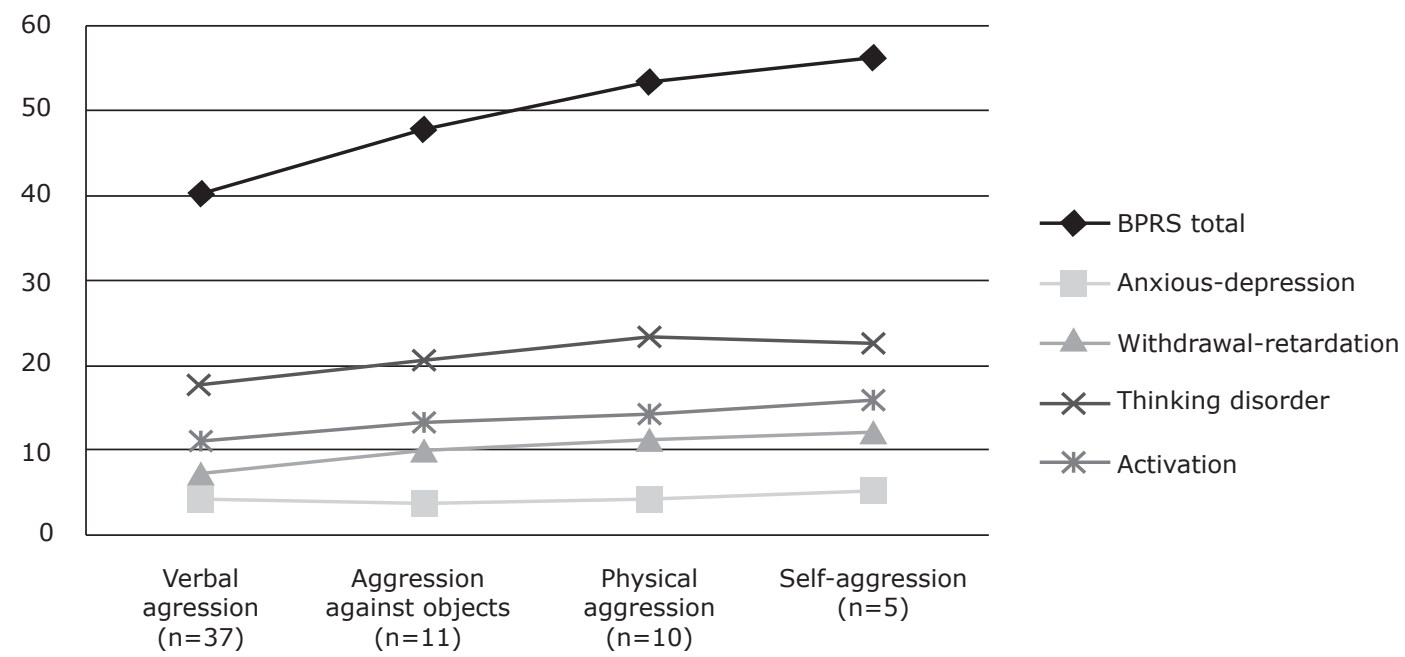

Figure 2 - Mean values of BPRS total score and its components according to the types of aggression. Groups include combined types of aggression (i.e., all verbally aggressive patients, not only verbally aggressive patients). BPRS = Brief Psychiatric Rating Scale.

The comparison of the subgroup of self-aggressive individuals with patients aggressive to others revealed that, in addition to psychomotor agitation and somatic anxiety, the self-aggressive patients also had more conceptual disorganization and disorientation/confusion, which was seen in their aggressive behavior. In fact, even aggressiveness itself was disorganized in these individuals, as their aggression had no objective or target and was chaotically expressed through psychomotor agitation and very intense psychosis.
The main limitation of this study was its relatively small sample, the consequent heterogeneity of its sample and the small proportion of the most severe types of aggression. Self-aggression was observed in patients with more severe pathologies, but, in most studies, physical aggression is the most serious form of aggression. Therefore, the proportion of severely disorganized patients in the self-aggressive group may be coincidental, rather than a constant in psychiatric emergency services.

Table 4 - Mean scores obtained on the Brief Psychiatric Rating Scale and comparison between hostile and violent patients $(n=51)$, and patients aggressive against others and self-aggressive patients $(n=53)$

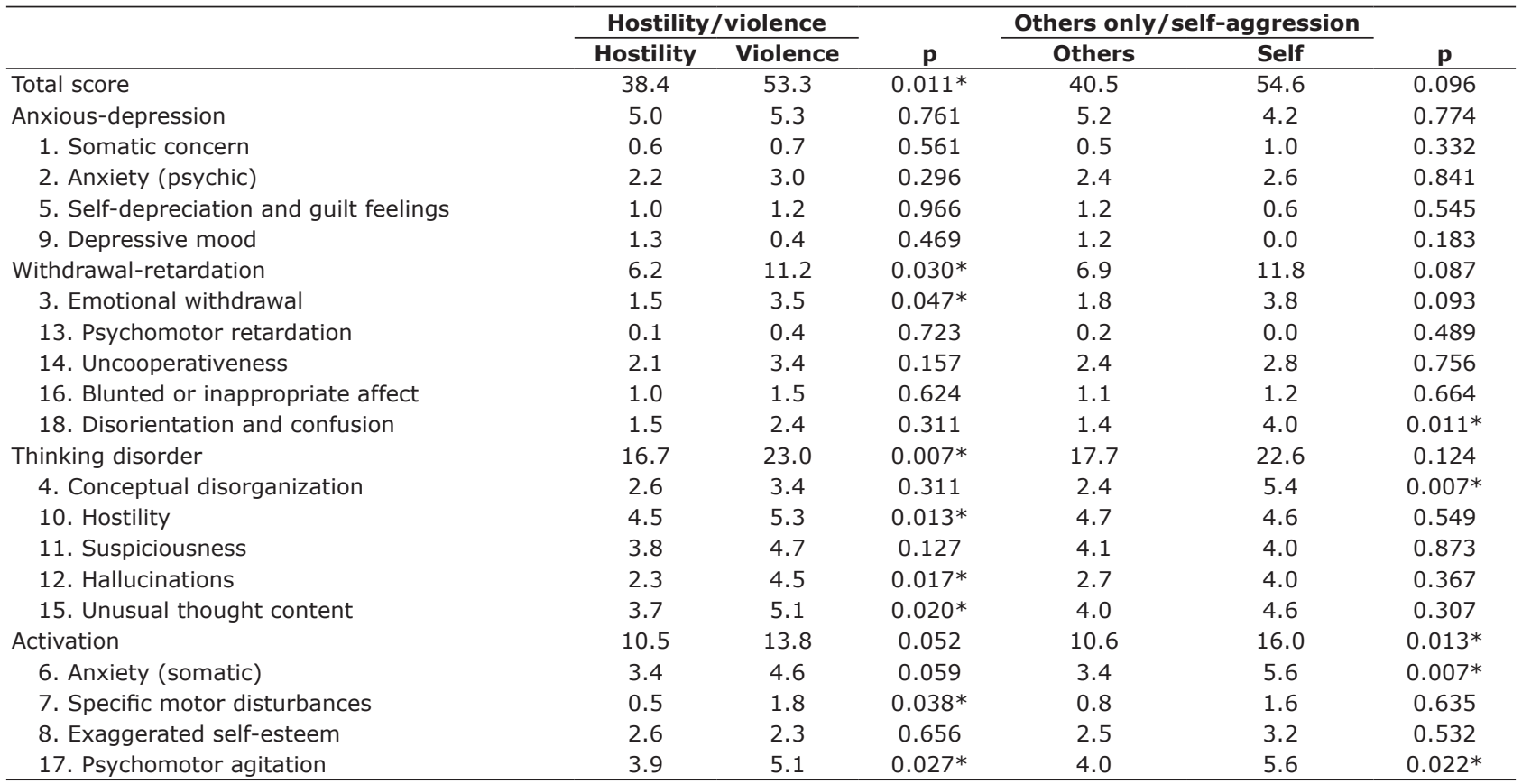

* Significant values. 
Another limitation was that the sample was quite heterogeneous regarding diagnoses. However, 83\% of the patients had psychosis as a common factor. The aggressive patients presented with psychosis and psychomotor agitation in which expansiveness, irritability, grandiose thoughts, paranoia and alterations of thinking characterize psychotic (medical related) aggressiveness. ${ }^{20-22}$ There were few patients with mental retardation or antisocial personality, and alcohol and cocaine use disorders were excluded. In such cases, aggression may not be related to psychosis, but to impulsiveness and character traits.

\section{Conclusion}

Aggression was associated with severity of psychopathology. In comparison with non-aggressive individuals, aggressive patients showed greater excitement, motor restlessness, hostility and lack of cooperation in the interview, as well as more disorganized thinking, grandiose ideas and paranoia. However, the main contribution of this study was to determine a positive association between severity of aggressive behavior and severity of psychopathology. These findings suggest that patients with severe hallucinations and delusions tend to be physically aggressive in the first 24 hours of hospitalization. Furthermore, agitated and psychotic patients who present with disorientation and disintegration of thought may be more likely to be aggressive in a chaotic way. Such patients should be managed with special care, constant observation, more intense chemical restraint, longer lasting motor restraint, assistance of guards as well as distance from relatives in the first hours after admission.

\section{Acknowledgements}

The study was supported by Programa de Bolsas de Iniciação Científica e Auxílio à Pesquisa Hospital Universitário de Santa Maria (PROIC-HUSM), Universidade Federal de Santa Maria (UFSM). We thank Dra. Anaelena Bragança de Moraes for her important contributions to statistical analysis.

\section{References}

1. Mantovani C, Migon, MN, Alheira FV, Del-Ben CM. Manejo do paciente agitado ou agressivo. Rev Bras Psiquiatr. 2010;32(Supl 2):S96-103.
2. Colasanti A, Natoli A, Moliterno D, Rossattini M, De Gaspari IF, Mauri MC. Psychiatric diagnosis and aggression before acute hospitalisation. Eur Psychiatry. 2008;23:441-8. Epub 2007 Nov 19.

3. Mulder CL, Uitenbroek D, Broer J, Lendemeijer B, van Veldhuizen JR, van Tilburg $W$, et al. Changing patterns in emergency involuntary admissions in the Netherlands in the period 20002004. Int J Law Psychiatry. 2008;31:331-6. Epub 2008 Jul 29.

4. Johnson ME. Violence on inpatient psychiatric units: state of the science. J Am Psychiatr Nurses Assoc. 2004;10:113-21.

5. Lanza ML, Zeiss R, Rierdan J. Violence against psychiatric nurses: sensitive research as science and intervention. Contemp Nurse. 2006;21:71-84

6. Cornaggia CM, Beghi $M$, Pavone $F$, Barale $F$. Aggression in psychiatry wards: a systematic review. Psychiatry Res. 2011;189:10-20. Epub 2011 Jan 13.

7. Steinert T. Prediction of inpatient violence. Acta Psychiatr Scand Suppl. 2002:133-41.

8. Overall J, Gorham DR. The Brief Psychiatric Rating Scale. Psychol Rep. 1962;10:799-812.

9. Shafer A. Meta-analysis of the brief psychiatric rating scale factor structure. Psychol Assess. 2005;17:324-35.

10. Amore M, Menchetti M, Tonti C, Scarlatti F, Lundgren E, Esposito $W$, et al. Predictors of violent behavior among acute psychiatric patients: clinical study. Psychiatry Clin Neurosci. 2008;62:247-55.

11. Biancosino B, Delmonte S, Grassi L, Santone G, Preti A, Miglio R, et al. Violent behavior in acute psychiatric inpatient facilities: a national survey in Italy. J Nerv Ment Dis. 2009;197:772-82.

12. Colasanti A, Paletta S, Moliterno D, Mazzocchi A, Mauri MC, Altamura AC. Symptom dimensions as predictors of clinical outcome, duration of hospitalization, and aggressive behaviours in acutely hospitalized patients with psychotic exacerbation. Clin Pract Epidemiol Ment Health. 2010;6:72-8.

13. Huber CG, Schöttle D, Lambert $M$, Hottenrott $B$, Agorastos $A$, Naber D, et al. Brief Psychiatric Rating Scale - Excited Component (BPRS-EC) and neuropsychological dysfunction predict aggression, suicidality, and involuntary treatment in first-episode psychosis. Schizophr Res. 2012;134:273-8.

14. Raja M, Azzoni A. Hostility and violence of acute psychiatric inpatients. Clin Pract Epidemiol Ment Health. 2005;1:11.

15. Romano $F$, Elkis $H$. Tradução e adaptação de um instrumento de avaliação psicopatológica das psicoses: a escala breve de avaliação psiquiátrica - versão ancorada (BPRS-A). J Bras Psiquiatr. 1996;45:43-9.

16. Crippa JA, Sanches RF, Hallak JE, Loureiro SR, Zuardi AW. A structured interview guide increases Brief Psychiatric Rating Scale reliability in raters with low clinical experience. Acta Psychiatr Scand. 2001;103:465-70.

17. Crippa JA, Sanches RF, Hallak JE, Loureiro SR, Zuardi AW. Factor structure of Bech's version of the Brief Psychiatric Rating Scale in Brazilian patients. Braz J Med Biol Res. 2002;35:1209-13.

18. Silver JM, Yudofsky SC. The Overt Aggression Scale: overview and guiding principles. J Neuropsychiatry Clin Neurosci. 1991;3:S22-9.

19. Mackinnon RA, Yudofsky SC. A avaliação psiquiátrica na prática clínica. Porto Alegre: Artes Médicas; 1988.

20. Quanbeck C. Forensic psychiatric aspects of inpatient violence. Psychiatr Clin North Am. 2006;29:743-60.

21. Barratt ES, Slaughter L. Defining, measuring, and predicting impulsive aggression: a heuristic model. Behav Sci Law. 1998; 16:285-302.

22. Barratt ES, Stanford MS, Felthous AR, Kent TA. The effects of phenytoin on impulsive and premeditated aggression: a controlled study. J Clin Psychopharmacol. 1997;17:341-9.

\section{Correspondence:}

Vitor Crestani Calegaro

Universidade Federal de Santa Maria

Departamento de Neuropsiquiatria

Centro de Ciências da Saúde

Av. Roraima, 1000

97105-900 - Santa Maria, RS - Brazil

Tel./Fax: +55 (55) 3220.8148 / 3025.7596

E-mail: vcalegaro@hotmail.com 